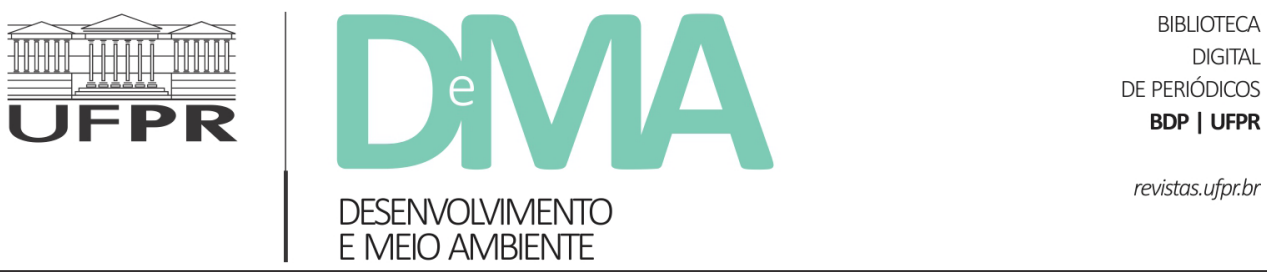

\title{
Análise de impactos da Reserva Biológica Marinha do Arvoredo sobre os serviços ecossistêmicos e os stakeholders
}

\section{Impact assessment of the Arvoredo Marine Biological Reserve on ecosystem services and its stakeholders}

\author{
Cleiton Luiz Foster JARDEWESKI ${ }^{* *}$, Rosemeri Carvalho MARENZI ${ }^{1}$, Junior Ruiz GARCIA ${ }^{2}$ \\ ${ }^{1}$ Universidade do Vale do Itajaí (UNIVALI), Itajaí, SC, Brasil. \\ ${ }^{2}$ Universidade Federal do Paraná (UFPR), Curitiba, PR, Brasil. \\ *E-mail de contato: cleitonlfj@yahoo.com.br
}

Artigo recebido em 10 de agosto de 2020, versão final aceita em 10 de fevereiro de 2021, publicado em 08 de dezembro de 2021.

RESUMO: O trabalho propõe uma análise de impactos de áreas marinhas protegidas que integre a análise de stakeholders e a avaliação de impactos sobre os serviços ecossistêmicos, a fim de ampliar o aprendizado social na adoção de estratégias de gestão e engajamento, utilizando a Reserva Biológica Marinha do Arvoredo (ReBio) como estudo de caso. Esta protege um arquipélago localizado no litoral de Santa Catarina, entre Florianópolis e Bombinhas, contribuindo para manutenção da biodiversidade e produção pesqueira da região. A integração metodológica teve três etapas: Mapeamento e Análise dos Stakeholders, Identificação dos Serviços Ecossistêmicos, e Análise dos impactos da ReBio Arvoredo sobre os serviços ecossistêmicos. Foram encontradas 21 categorias de partes interessadas, distribuídas em todos os 8 grupamentos possíveis e possuindo características distintas de engajamento: poder, legitimidade e rede de relacionamento. Um total de 21 serviços ecossistêmicos marinhos foram identificados, sendo dois de provisão, oito de regulação e onze culturais. A análise dos impactos sobre os serviços ecossistêmicos e os stakeholders possibilitou verificar cinco impactos negativos e dezesseis impactos positivos decorrentes da implementação e manutenção da ReBio, todos os impactos se distribuem de maneira diferenciada e com intensidades variadas. A metodologia conseguiu enaltecer a interdependência das implicações sociais da gestão por meio do entendimento dos impactos sobre os serviços ecossistêmicos e os efeitos sobre os stakeholders categorizados, destacando os principais pontos a serem trabalhados no relacionamento da ReBio com seu entorno. Esta abordagem pode ser replicada em outras áreas protegidas e o conhecimento produzido pode ser usado para mudar crenças e entendimentos sobre o papel dos ecossistemas no bem-estar humano e, estrategicamente, ajudar os órgãos ambientais na articulação e comunicação de seus interesses em mitigar a distribuição de impactos negativos e a ampliação da repartição dos benefícios gerados pelas unidades de conservação brasileiras. 
Palavras-chave: serviços ecossistêmicos; reserva biológica marinha do arvoredo; análise de impacto; stakeholders; gestão ambiental estratégica.

ABSTRACT: The research proposes an impact analysis of marine protected areas integrating a stakeholder analysis and ecosystem services impact assessment, in order to expand social learning and help the adoption of new management and engagement strategies, using the Reserva Biológica Marinha do Arvoredo (ReBio) as a case study. ReBio protects an archipelago located on the coast of Santa Catarina, between Florianópolis and Bombinhas, contributing to biodiversity maintenance and fisheries production in the region. The methodological integration had three stages: Stakeholders Mapping and Analysis, Ecosystem Services Identification and Impact Assessment on ecosystem services. Twenty-one stakeholders categories were found, distributed in all 8 possible groups with different engagement characteristics: power, legitimacy and relationship network. A total of twenty-one marine ecosystem services have been identified, two are provision, eight are regulation and eleven are cultural ecosystem services. The impact assessment on ecosystem services and stakeholders made it possible to verify five negative impacts and sixteen positive impacts, resulting from the creation and maintenance of ReBio activities, all impacts are differently distributed and have varying intensities. The method adopted was able to highlight the interdependence of the social implications of management decisions by understanding the impacts on ecosystem services and this effects on the stakeholders, this result highlights the main issues to be worked on future relationship between ReBio and its surroundings. This approach can be replicated in other protected areas and the knowledge produced can be used to change beliefs and understandings about the role of ecosystems in human well-being and, strategically, help environmental agencies in articulating and communicating their interests to mitigate the distribution of negative impacts and the enhancement of shared benefits generated by Brazilian conservation units.

Keywords: ecosystem services; reserva biológica marinha do arvoredo; impact analysis; stakeholders; strategic environmental management.

\section{Introdução}

O estado brasileiro é signatário de diversos tratados e compromissos internacionais de meio ambiente, tais como a convenção da diversidade biológica (Alencar, 1996), meta de Aichi e dos ODS (Objetivos do Desenvolvimento Sustentável). Contudo, apresenta contradições na execução de sua agenda ambiental (Medeiros, 2006), pois não investe suficientemente em suas agências governamentais que lideram a execução dessas metas em âmbito nacional. Dentro deste cenário estabelecido, aparecem janelas políticas que buscam analisar a eficiência das Unidades de Conservação (UCs) como estratégia de promoção e garantia da con- servação da biodiversidade (Pomeroy et al., 2004; Hockings et al., 2006).

No entanto, esta oportunidade de eficiência de UCs pode servir a interesses distintos, tais como contradizer seus benefícios em detrimento de alternativas de desenvolvimento com altos impactos ambientais, desconstruir as políticas públicas pelo aparelhamento do estado e clientelismo de coalizações partidárias (Sales, 2017), ou ainda, servir para proselitismos conservacionistas que, muitas vezes, pela guisa da participação e colaboração, negligenciam as comunidades tradicionais e atores dependentes dos serviços ecossistêmicos (Garnet et al., 2018).

Sales (2017) ressalta que a gestão participativa na administração pública brasileira e nas políticas 
de conservação de espécies marinhas ameaçadas, transmutou para um "participatismo", através da flexibilização de normas e teorias que trouxeram um aspecto caricatural e pejorativo, servindo muito mais para propagar tentativas de modernização ou justificar planos "estratégicos". Entretanto, o desafio permanece e o pensamento conservacionista precisa propor abordagens que busquem diminuir a dificuldade de comunicação entre as partes, a superação dos conflitos e a negociação de interesses comuns que preconizem a proteção da biodiversidade. Pensar estas questões de conservação, na perspectiva dos riscos ecológicos nas sociedades complexas, envolve, necessariamente, a ideia de sistema e seus conceitos correlatos, tais como: ordem, desordem, complexidade e irreversibilidade. Significa trazer para a discussão tais conceitos, fundamentais de uma teoria capaz de abordar problemas de outros ângulos, diferentes daqueles cobertos pelas abordagens correntes (Amaro, 2013).

A complexidade de um sistema é caracterizada quando a evidência apoia hipóteses conflitantes e esta contradição não pode ser resolvida dentro do tempo disponível para a questão em análise (Snowden, 2018). Considerar esta complexidade sugere que a possibilidade de busca de um desenvolvimento sustentável, depende da mudança de percepção da sociedade humana em enxergar os sistemas complexos envolvidos. Assim, é essencial mudar a percepção dos atores sociais, deslocando sua atenção do aumento da capacidade produtiva, para o aumento da capacidade adaptativa. Representa voltar a atenção dos atores sociais para uma visão em que a sociedade e a natureza estão coevoluindo na biosfera (Zurlini et al., 2008).

Dentro desta perspectiva, despertar a percepção para os serviços ecossistêmicos providos à sociedade, pode ser uma maneira de sensibilizar os atores sociais para a necessidade de conservação dos recursos naturais e da biodiversidade. Os serviços ecossistêmicos (SE), definidos pelo Millenium Ecosystem Assessment, são os benefícios que as pessoas obtêm dos ecossistemas, estes incluem alimento, água, madeira, valores culturais, etc., e são os resultados procurados pela gestão de ecossistemas (Wallace, 2007).

As teorias dentro do escopo da conservação brasileira, trazem historicamente conceitos supostamente inovadores, tais como a gestão baseada em ecossistemas, os sistemas adaptativos complexos, os sistemas socioecológicos e os serviços ecossistêmicos, contudo, ainda faltam evidências de sucesso na operacionalização destas teorias no âmbito da administração pública, seja por disfunções burocráticas, falta de flexibilidade ou a imprecisão conceitual presente em normas ambíguas (Sales, 2010; 2017).

Portanto, os desafios e deficiências das políticas públicas de conservação marinha brasileira permanecem, tais como o formalismo exacerbado e as barreiras linguísticas na aproximação com os públicos de interesse e a população em geral, observando-se a dificuldade de comunicação e aceitação da importância da conservação da biodiversidade (Gujit 1999; Evans \& Guariguata 2008; Fortmann 2008; Chevalier \& Buckles 2013; Chuenpagdee et al.2013; Voyer et al., 2015) ou, ainda, de integração com estratégias de geração de renda ou de política pública, ambas em escala regional, denotando uma baixa articulação (Anderies et al., 2004; Smith \& Stirling, 2010; Dare et al., 2014).

A emergência da participação pública nas políticas ambientais, tais como a gestão de unidades de conservação, vem sendo incorporada cada vez mais, desde a aprovação do SNUC (Sistema Nacio- 
nal de Unidades de Conservação), em 2000, tanto no contexto nacional como internacional (Pretty \& Vodouhe, 1998; Reed et al., 2009). O reconhecimento dos tomadores de decisão tem provocado a necessidade de compreender quem é afetado pelas decisões e quem tem poder de influência nos seus resultados, isto é, os stakeholders ou partes interessadas (Freeman, 1984).

Diante deste contexto, percebe-se que a análise de stakeholders se mostra como um método para examinar as relações de poder entre grupos e indivíduos e seus respectivos interesses em um serviço ecossistêmico, recurso natural ou situação. Este método ajuda a identificar as principais diferenças entre grupos e questões potenciais de terreno comum, para acordos e intervenções viáveis que visem um aperfeiçoamento da gestão dos recursos naturais. A teoria e a prática das partes interessadas são muito promissoras no sentido de promover o envolvimento sistemático de atores e um foco pragmático em problemas a serem resolvidos (Chevalier \& Buckles, 2013).

A teoria da complexidade, que deve incluir stakeholders, aponta novas oportunidades de integração entre a teoria do planejamento e a governança ambiental, através da perspectiva do aprendizado social. Esta contribui sobremaneira nas tomadas de decisão, sendo que alguns trabalhos na área destacam a importância de integrar sistemas sociais e ecológicos (Medeiros et al., 2013; Marques, 2017), destacando a importância da aprendizagem e seus contextos para fins decisórios (Zurlini et al., 2008; Alexander et al., 2014).

Poucas teorias de gestão tratam do distanciamento linguístico entre as partes e o desafio de construção de entendimentos comuns, Boisot (1998) e Snowden (2010) conseguiram trazer esta perspectiva para uma prática. Outros trabalhos também exploraram a análise de impacto sobre os serviços ecossistêmicos (Bowd et al., 2015) e a busca de abordagens mais amplas que reconciliam e integram aspectos da sustentabilidade, através do grau de compreensão (Hackin \& Guthrie, 2008).

Não é por falta de propostas ou formalismos metodológicos, mas é tácita a dificuldade de associação de metodologias com as contradições da gestão das áreas marinhas protegidas (AMP) brasileiras (Sales, 2017). Além disto, a criação e o estabelecimento de AMP não geram apenas impactos positivos, muitas vezes os impactos negativos são negligenciados e acabam por gerar problemas futuros para a gestão (Bennett \& Dearden 2014; Sowman \& Sunde, 2018). Schreckenberg et al. (2010) elencaram várias abordagens para verificar a atribuição e maneiras de garantir que os impactos em diferentes níveis sejam considerados nas unidades de conservação, mas destacaram que várias questões, lacunas e problemas permanecem sem solução nas metodologias correntes.

Face ao contexto, o propósito deste artigo não é apenas trazer críticas de gestão, mas indicar possibilidades metodológicas que possam acrescentar melhorias nas ações e resultados na conservação de espaços marinhos protegidos. É fundamental ser claro sobre o papel, o potencial e as limitações de todas as formas de evidências para melhorar o entendimento e informar as políticas e práticas de conservação (Adams \& Sandbrook, 2013; Pullin et al., 2013; Bennet, 2016), pois produzir ações e resultados eficazes de conservação requer uma visão ampla da ciência da conservação (Kareiva \& Marvier 2012; de Snoo et al. 2013; Bennett \& Roth, 2015). 
Assim, o presente trabalho tem como objetivo analisar os impactos sobre os serviços ecossistêmicos da Reserva Biológica do Arvoredo, por meio de abordagem metodológica que integra os stakeholders, e propiciar informações que possam ser utilizadas para identificar lacunas e ampliar o aprendizado social na adoção de estratégias de gestão e engajamento em unidades de conservação brasileiras.

\section{Metodologia}

\section{1. Área de estudo}

A Reserva Biológica Marinha do Arvoredo (ReBio Arvoredo) localiza-se no litoral de Santa Catarina, entre os municípios de Florianópolis e Bombinhas, possui 17.600 hectares de superfície e abriga em seu interior as Ilhas do Arvoredo, Galé, Deserta, Calhau de São Pedro e uma grande área marinha que circunda esse arquipélago (Figura 1). Foi criada pelo Decreto ${ }^{\circ}$ 99.142, de 12 de março de 1990 e é uma unidade de conservação federal, de proteção integral, tendo como objetivo principal proteger uma região costeira com grande importância biológica, contribuindo para manutenção da biodiversidade e produção pesqueira de seu entorno (IBAMA, 2004).

A alta diversidade dos ambientes marinhos e terrestres (Mata Atlântica) existentes dentro da Reserva, abriga uma infinidade de espécies, segundo Segal et al. (2017), existem mais de 1.600 espécies marinhas e terrestres na região, muitas das quais ainda precisam ser estudadas em maior detalhe. Destas, segundo os autores, cerca de 26 espécies ameaçadas de extinção estão presentes na região e, ao menos, 20 espécies são consideradas exóticas, tais como o Coral-Sol (Tubastrea coccinea), alertando para a importância do manejo do ambiente.

As ilhas apresentam remanescentes de Mata Atlântica, locais de reprodução para aves marinhas e sítios arqueológicos com sambaquis e inscrições rupestres dos povos antigos. Além disso, os ambientes marinhos da ReBio Arvoredo fornecem abrigo para reprodução e crescimento de diversas espécies de peixes, o que contribui para manutenção dos estoques pesqueiros no seu entorno (IBAMA, 2004).

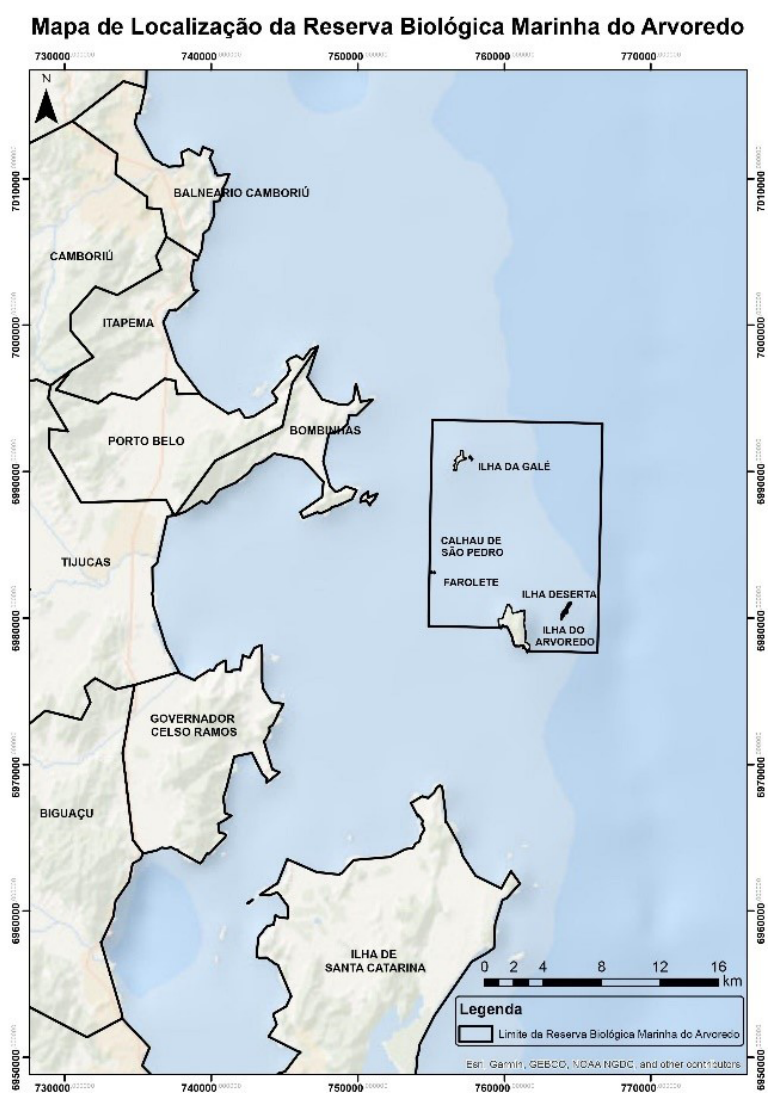

FIGURA 1 - Localização da Reserva Biológica Marinha do Arvoredo. 
A ReBio Arvoredo é um importante ativo de pesquisas acadêmicas, com uma série de estudos e trabalhos realizados em seu entorno. Existe uma proeminência de estudos ecológicos, sendo que alguns trabalhos abordam questões de gestão compartilhada (Costa, 2003), monitoramento ambiental (Strenzel, 1997), zoneamento marinho (Chludinski, 2002), conflitos (Vivacqua, 2005), pesca (Wahrlich, 1999), recategorização (Fischer, 2015) e gestão participativa (Pretto \& Marimon, 2017).

\subsection{Procedimento metodológico}

A metodologia desenvolvida foi uma integração adaptativa de três abordagens distintas: mapeamento de stakeholders, identificação de serviços ecossistêmicos e análise de impacto sobre os serviços ecossistêmicos considerando os stakeholders.

Os stakeholders foram mapeados com base nos resultados do trabalho de Pretto \& Marimon (2017), no plano de manejo (IBAMA, 2004) e nas participações em reuniões do Conselho Gestor (CorBio). Os setores socioeconômicos e as instituições correlacionadas aos serviços ecossistêmicos da ReBio Arvoredo foram levantados para criar categorias de stakeholders, sendo posteriormente analisadas e subdivididas em grupamentos de acordo com o modelo estipulado por Mitchel et al. (1997). Este modelo utiliza três características diferentes para classificação dos stakeholders: legitimidade ${ }^{1}$, poder/ autoridade $^{2}$, e rede de relacionamento ${ }^{3}$. Além destas, estabelece categorias, sendo estas classificadas de acordo com a relação do stakeholder com o Conselho da ReBio Arvoredo, e intensidade (alta ou baixa) das três características.

Os serviços ecossistêmicos marinhos foram identificados utilizando uma listagem adaptada das tipologias propostas por Henrichs et al. (2013), Liquete et al. (2013) e Haines-Young \& Potschin (2018), reunindo uma síntese explicativa mais próxima ao léxico perceptivo dos stakeholders. A validação da existência, ou não, de um serviço ecossistêmico depende do contexto socioecológico e a obediência à duas cláusulas específicas: uma é o fornecimento de um fluxo ou resultado do sistema ecológico e a outra é se isso gera um comportamento, uma percepção ou um recurso utilizado para benefício da sociedade ou da comunidade local (UNEP et al., 2017). Portanto, um ecossistema fornece um conjunto de serviços ecossistêmicos que contribuem à sociedade de várias maneiras e com situações e recortes diferenciados. No presente estudo, por exemplo, a pesca dentro dos limites da ReBio é proibida e, portanto, não existe esse serviço ecossistêmico, mas verifica-se um efeito de borda, em que a pesca é explorada intensamente nas

\footnotetext{
${ }^{1}$ Legitimidade: "percepção ou suposição generalizada de que as ações de uma entidade são desejáveis, apropriadas em algum sistema socialmente construído de normas, valores, crenças e definições" (Suchman, 1995 apud Mitchel et al., 1997). A definição sugerida por Suchman é ampla e reconhece a natureza avaliativa, cognitiva e socialmente construída da legitimidade (Mitchel et al., 1997).

${ }^{2}$ Poder/Autoridade: "a probabilidade de um ator dentro de um relacionamento social estar em posição de realizar sua própria vontade, apesar da resistência" (Weber, 1947 apud Mitchel et al., 1997). Portanto, uma parte em um relacionamento tem poder, na medida em que tem ou pode obter acesso a meios coercitivos, utilitários ou normativos, para impor sua vontade no relacionamento (Mitchel et al., 1997).

${ }^{3}$ Rede de Relacionamento: Número de Relações sociais de um Stakeholder. De acordo com Bodin \& Crona (2009), uma hipótese inicial razoável seria que, quanto mais laços sociais, mais possibilidades de ação conjunta e outro tipo de colaborações que ajudariam os atores a evitar conflitos ferozes de recursos e, em vez disso, facilitassem o desenvolvimento de regulamentos comuns de recursos, ou seja, quanto maior a densidade da rede (número de vínculos existentes), maior o potencial de ação coletiva.
} 
cercanias da ReBio (PETROBRAS, 2017), e nesta situação o serviço ecossistêmico existe em sua área de influência.

A partir destes resultados foi possível realizar a análise dos impactos causados pela criação e manutenção da ReBio sobre os serviços ecossistêmicos e sua distribuição entre os stakeholders, sendo utilizada a metodologia proposta por Landsberg et al. (2014), que determina a sensibilidade e a magnitude destes impactos sobre os stakeholders. Os impactos sobre os serviços ecossistêmicos listados foram analisados individualmente sobre as categorias de stakeholders identificadas. Os critérios utilizados foram: se o impacto era positivo ou negativo, se os seus efeitos eram diretos ou indiretos, a sensibilidade dos atores sociais em relação à mudança nos serviços (alta, média e baixa), e a magnitude da perda ou do ganho associado à mudança nos serviços ecossistêmicos (insignificante, baixa, média ou alta). O trabalho de Barnaud et al. (2018) também foi utilizado para entender sinergias e antagonismos entre os serviços ecossistêmicos, dentro do espectro da ação coletiva de uma unidade de conservação marinha.

\section{Resultados e discussão}

\subsection{Mapeamento de stakeholders}

Na ReBio Arvoredo foram encontradas 21 categorias de partes interessadas, distribuídas em todos os oito grupamentos possíveis (Tabela $1 \mathrm{e}$ Figura 2). Mannetti et al. (2019) adotando metodologia similar em um Parque Nacional da Namíbia encontrou 12 categorias de stakeholders.
Observamos que a principal agência ambiental federal responsável pela gestão de Unidades de Conservação, representado pelo ICMBio, e o conselho gestor da ReBio Arvoredo (Corbio) estão no centro do diagrama, sendo os stakeholders definidores, pois articulam toda a rede de atores através do Corbio, equilibrando sua relação com forte autoridade e redundante legitimidade.

Verifica-se que a Polícia Federal e as Universidades (UFSC e UNIVALI) são categorias de stakeholders com forte autoridade e uma ampla gama de relacionamentos, cabe citar que aqui a autoridade se manifesta de duas maneiras, tal como o poder e força da fiscalização realizada pela Polícia Federal e as autoridades científicas que podem ser encaradas como um campo de grande influência nas decisões técnicas acerca da biodiversidade e proteção dos ambientes marinhos. Um outro grupo de stakeholders com grande legitimidade e uma ampla rede de relacionamentos agrega os principais representantes dos usuários dos serviços ecossistêmicos, tais como as empresas de mergulho, as colônias de pesca e o sindicato da pesca industrial de Itajaí. As ONGs ambientalistas também fazem parte deste agrupamento, devido a sua representação simbólica de conservação da natureza e associação com diversas redes de apoio.

Os Órgãos Municipais de Meio Ambiente e os Órgãos de Turismo da região representam um grupo de atores que possuem alta legitimidade e alta autoridade, representando principalmente o poder local associado ao meio ambiente e ao turismo, no entanto as secretarias e agências de turismo encontram-se distanciadas da ReBio do Arvoredo, provavelmente pelo seu caráter de proteção integral e falta de políticas ou parcerias que melhor conjuguem a conservação da natureza com iniciativas de turismo. 
TABELA 1 - Categorias de stakeholders identificados na ReBio Arvoredo.

\section{Stakeholder}

Instituto Chico Mendes da Biodiversidade (ICMBio)

Conselho da ReBio Arvoredo (CorBio)

Polícia Federa

Órgãos Municipais de Meio Ambiente

Sind. Armadores e das Ind. da Pesca de Itajaí e Região (SINDIPI)

Pescadores Artesanais

Colônias de Pescadores

Órgãos de Turismo

Comitê da Bacia do Rio Tijucas

ONGs Ambientalistas

Empresas de Mergulho

Mergulhadores

Associações Náuticas

Turistas

Aquicultores

Pescadores Esportivos

Caçadores Submarinos

Empresa de Pesq. Agropec. e Extensão Rural de SC (EPAGRI)
Marinha do Brasil

Universidades

Federação dos Pescadores do Estado de Santa Catarina (FEPESC)

\section{Legitimidade}

Autoridade

Rede de Relacionamento

\begin{tabular}{|c|c|}
\hline 1 & 1 \\
\hline 1 & 1 \\
\hline 0 & 1 \\
\hline 0 & 1 \\
\hline 1 & 1 \\
\hline 0 & 1 \\
\hline 1 & 0 \\
\hline 1 & 0 \\
\hline 1 & 0 \\
\hline 1 & 1 \\
\hline 0 & 0 \\
\hline 1 & 0 \\
\hline 1 & 0 \\
\hline 1 & 0 \\
\hline 0 & 0 \\
\hline 0 & 0 \\
\hline 0 & 0 \\
\hline 1 & 0 \\
\hline 1 & 0 \\
\hline 0 & 0 \\
\hline 1 & 0 \\
\hline
\end{tabular}

* Intensidade do atributo: $1=$ Alta; $0=$ Baixa

\section{1}

1

0

1

0

1 


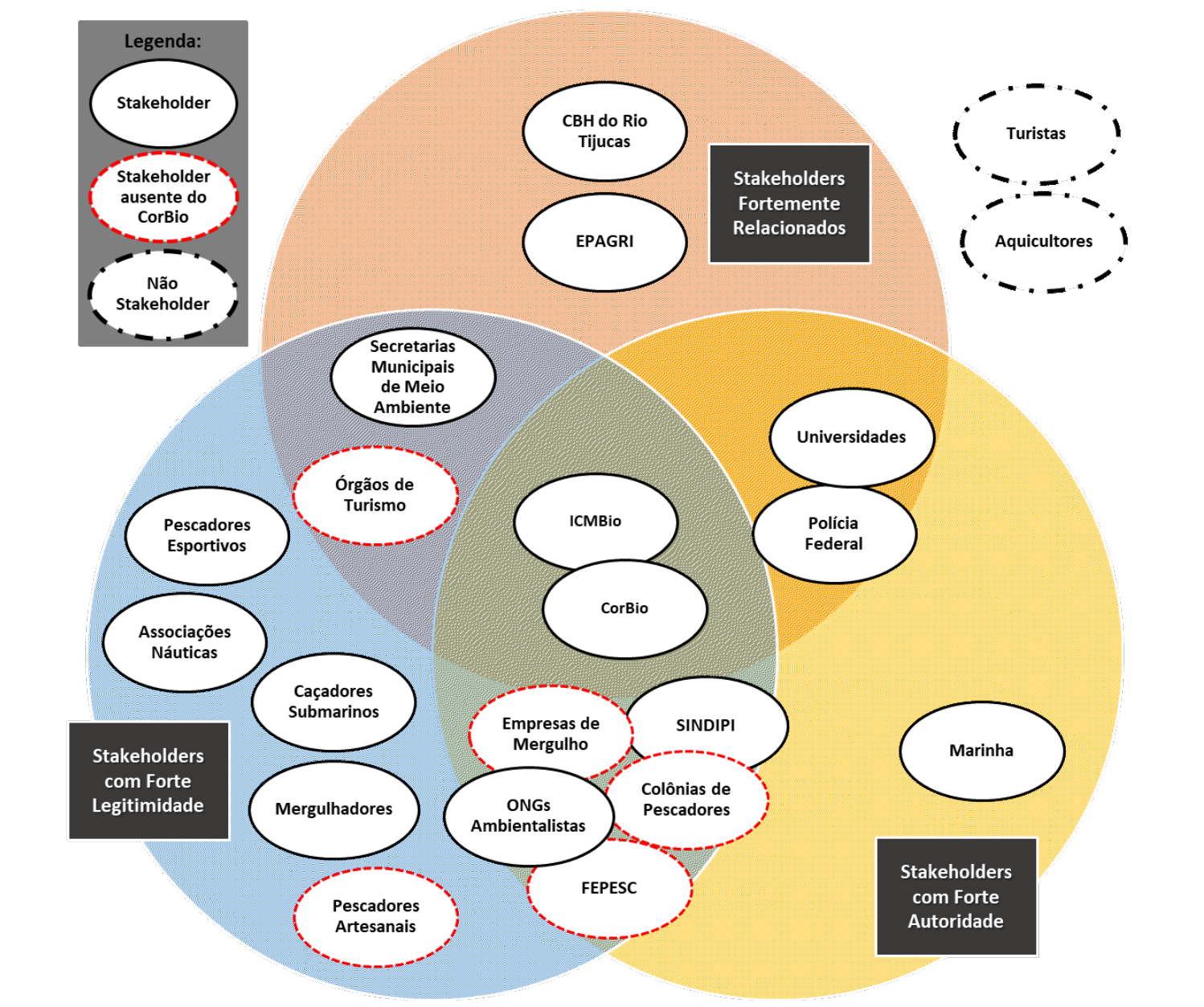

FIGURA 2 - Categorias de stakeholders da Reserva Biológica Marinha do Arvoredo.

As outras categorias de atores sociais identificados encontram-se em apenas uma esfera no caso da Marinha (autoridade), Comitê da Bacia Hidrográfica do Rio Tijucas e EPAGRI (relação), e os mergulhadores, o setor náutico e os pescadores esportivos e os pescadores artesanais (legitimidade). Cabe destacar que, apesar de "baixo engajamento" da Marinha, as ilhas do Arvoredo, Galé e Calhau de São Pedro estão sob sua jurisdição, pois abrigam instalações militares: um farol na Ilha do Arvoredo e pequenos faroletes nas outras duas ilhas, além de uma edificação antiga utilizada pelo ICMBio para atividades de proteção e pesquisa, havendo um acordo de cooperação técnica entre estas duas instituições (ICMBio, 2020).

Outros stakeholders não foram considerados, podendo ser chamados de "não-atores", pois não pertencem ou não participam historicamente da 
esfera de atuação coletiva (Barnaud et al., 2018) da ReBio Arvoredo, tais como os turistas e os aquicultores, apesar de serem grupos com atividades expressivas em Bombinhas e Florianópolis.

Pode se verificar que atualmente existem alguns atores ausentes no CorBio (destacadas em vermelho na figura), tais como as colônias de pesca, as operadoras de mergulho, os pescadores esportivos e os órgãos de turismo (agências e secretarias de turismo). Alguns conflitos de interesse causaram esse distanciamento, tais como as dificuldades de atividades impostas pela criação da ReBio e a incompatibilidade de uso da unidade como local para atividades turísticas e quebras na continuidade da relação.

\subsection{Serviços ecossistêmicos}

Dos 56 serviços ecossistêmicos (SE) contidos na listagem mais recente (Haines-Young \& Potschin, 2018), 21 obedeceram às duas cláusulas de identificação de um serviço ecossistêmico na ReBio Arvoredo, sendo: dois (2) serviços ecossistêmicos de provisão, oito (8) de regulação e onze (11) culturais (Tabela 2). Os SE não listados restantes, não configuraram nenhum tipo de uso, apesar de alguns possuírem potencial de utilização, como por exemplo o uso de recursos genéticos para manter ou estabelecer populações, pois não foi encontrado iniciativa desta natureza em curso na região, não configurando um SE propriamente dito.

Palomo et al. (2013) levantaram 11 SE para o Parque Nacional de Donãna, na Costa, e 12 para o Parque Nacional Sierra Nevada, em região montanhosa, ambos na Espanha, sendo: 3 e 2 de provisão, 1 e 5 de regulação, 7 e 5 cultural, respectivamente.
Especificamente para Áreas Marinhas Protegidas, 25 tipos de SE foram levantados em cinco áreas no Reino Unido, sendo que os autores atentam que a extensão e a qualidade dos serviços e os bens/ benefícios fornecidos à sociedade devem ser vistos como uma característica inerente à designação de AMP e o processo de gestão (Potts et al., 2014). Assim, apesar de que o conceito dos serviços ecossistêmicos ter sido cada vez mais utilizado, alguns desafios institucionais na operacionalização deste conhecimento são raramente reportados de maneira satisfatória (Dick et al., 2017).

Os serviços de provisão estão associados principalmente a questão do extrativismo marinho, principalmente a pesca, enquanto os serviços de regulação dizem respeito à transformação de insumos bioquímicos ou físicos dos ecossistemas e a regulação das condições físicas, químicas ou biológicas, tais como proteção costeira (refúgio para embarcações), atenuação do impacto visual da paisagem costeira urbanizada, dispersão de gametas, manutenção do ciclo de vida das espécies, regulação do clima e controle de pestes e doenças no ambiente marinho (bioinvasões e marés vermelhas). Os serviços culturais estão ligados às interações físicas, intelectuais, espirituais e simbólicas com o ambiente da ReBio Arvoredo, tais como a recreação (mergulho e pesca esportiva), ao turismo, ao conhecimento (científico e local), a cultura, ao valor de existência e ao legado para as futuras gerações.

Destaca-se o grande número de SE culturais encontrados na Reserva Biológica Marinha, pois mesmo com restrições de uso, a contemplação da paisagem, a observação de aves e organismos marinhos, a possibilidade de atividades educativas e científicas, e a espiritualidade associada a UC, incorrem em benefícios. Na Área de Proteção 
TABELA 2 - Serviços ecossistêmicos da ReBio Arvoredo.

\begin{tabular}{|c|c|c|c|c|c|c|c|c|}
\hline $\mathbf{N}$ & Seção & Divisão & Grupo & Classe & Descrição Simples & Clausula Ecológica & Clausula de Uso & $\begin{array}{c}\text { Evidência do SE na ReBio } \\
\text { Arvoredo }\end{array}$ \\
\hline 1 & \multirow{2}{*}{ 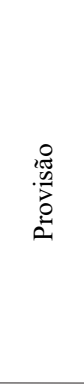 } & \multirow[b]{2}{*}{ Biomassa } & $\begin{array}{l}\text { Plantas Sel- } \\
\text { vagens para } \\
\text { nutrição, } \\
\text { materiais ou } \\
\text { energia }\end{array}$ & $\begin{array}{l}\text { Plantas Selva- } \\
\text { gens para nu- } \\
\text { trição }\end{array}$ & $\begin{array}{l}\text { Algas e Plantas para } \\
\text { nutrição }\end{array}$ & $\begin{array}{l}\text { Partes da biomassa } \\
\text { permanente de uma } \\
\text { espécie vegetal não } \\
\text { cultivada }\end{array}$ & $\begin{array}{l}\text { que podem ser } \\
\text { colhidas e utilizadas } \\
\text { para a produção de } \\
\text { alimentos }\end{array}$ & $\begin{array}{l}\text { Vegetais e fungos terrestres; } \\
\text { Macroalgas bentônicas e } \\
\text { macrófitas que podem ser } \\
\text { colhidas na zona rasa do litoral }\end{array}$ \\
\hline 2 & & & $\begin{array}{l}\text { Animais } \\
\text { Selva- } \\
\text { gens para } \\
\text { nutrição, } \\
\text { materiais ou } \\
\text { energia }\end{array}$ & $\begin{array}{l}\text { Animais Sel- } \\
\text { vagens para } \\
\text { nutrição }\end{array}$ & $\begin{array}{l}\text { Animais Selvagens } \\
\text { para nutrição }\end{array}$ & $\begin{array}{l}\text { Espécies de animais } \\
\text { selvagens (não do- } \\
\text { mesticadas) e seus } \\
\text { resultados... }\end{array}$ & $\begin{array}{l}\text { que podem ser usa- } \\
\text { dos como matéria- } \\
\text {-prima para a produ- } \\
\text { ção de alimentos }\end{array}$ & $\begin{array}{l}\text { Recursos Pesqueiros: Peixes } \\
\text { demersais (Garoupas, Badejos, } \\
\text { Corvinas); Peixes Pelágicos } \\
\text { (Cavalas, Anchovas) explo- } \\
\text { rados nas cercanias da ReBio } \\
\text { Arvoredo }\end{array}$ \\
\hline 3 & \multirow{3}{*}{ 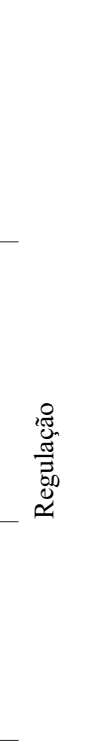 } & $\begin{array}{l}\text { Transfor- } \\
\text { mação de } \\
\text { insumos } \\
\text { bioquímicos } \\
\text { ou físicos } \\
\text { em ecossis- } \\
\text { temas }\end{array}$ & $\begin{array}{l}\text { Mediação de } \\
\text { perturbações } \\
\text { de origem } \\
\text { antropogê- } \\
\text { nica }\end{array}$ & Alívio visual & $\begin{array}{l}\text { Atenuação e Alívio } \\
\text { Visual }\end{array}$ & $\begin{array}{l}\text { A redução no im- } \\
\text { pacto visual das } \\
\text { estruturas humanas } \\
\text { nas pessoas... }\end{array}$ & $\begin{array}{l}\text { que atenua seu } \\
\text { efeito prejudicial } \\
\text { ou estressante, ou o } \\
\text { custo do incômodo }\end{array}$ & $\begin{array}{l}\text { Redução do Impacto Visual da } \\
\text { paisagem costeira urbanizada }\end{array}$ \\
\hline 4 & & \multirow{3}{*}{$\begin{array}{l}\text { Regulação } \\
\text { de condi- } \\
\text { ções físicas, } \\
\text { químicas e } \\
\text { biológicas }\end{array}$} & $\begin{array}{l}\text { Regulação } \\
\text { de fluxos de } \\
\text { linha de base } \\
\text { e eventos } \\
\text { extremos }\end{array}$ & $\begin{array}{l}\text { Regulação do ci- } \\
\text { clo hidrológico e } \\
\text { do fluxo de água } \\
\text { (incluindo con- } \\
\text { trole de inunda- } \\
\text { ções e proteção } \\
\text { costeira) }\end{array}$ & $\begin{array}{l}\text { Regulando os fluxos } \\
\text { de água em nosso } \\
\text { meio ambiente }\end{array}$ & $\begin{array}{l}\text { A regulação dos } \\
\text { fluxos de água em } \\
\text { virtude das proprie- } \\
\text { dades ou caracte- } \\
\text { rísticas químicas e } \\
\text { físicas dos ecossis- } \\
\text { temas }\end{array}$ & $\begin{array}{l}\text { que ajudam as } \\
\text { pessoas no gerencia- } \\
\text { mento e uso de sis- } \\
\text { temas hidrológicos } \\
\text { e mitigam ou evita } \\
\text { possíveis danos ao } \\
\text { uso humano, à saú- } \\
\text { de ou à segurança }\end{array}$ & $\begin{array}{l}\text { Local de proteção e refúgio } \\
\text { para embarcações em ocasiões } \\
\text { de tempestades e mal tempo }\end{array}$ \\
\hline 5 & & & \multirow{2}{*}{$\begin{array}{l}\text { Manutenção } \\
\text { do ciclo } \\
\text { de vida, } \\
\text { proteção de } \\
\text { habitat e de } \\
\text { pool gené- } \\
\text { tico }\end{array}$} & $\begin{array}{l}\text { Polinização (ou } \\
\text { dispersão de } \\
\text { 'gametas' em } \\
\text { contexto mari- } \\
\text { nho) }\end{array}$ & $\begin{array}{l}\text { Polinizando nossas } \\
\text { árvores frutíferas e } \\
\text { outras plantas }\end{array}$ & $\begin{array}{l}\text { fertilização de cul- } \\
\text { turas por plantas ou } \\
\text { animais }\end{array}$ & $\begin{array}{l}\text { que mantém ou au- } \\
\text { menta a abundância } \\
\text { e / ou diversidade de } \\
\text { outras espécies que } \\
\text { as pessoas usam ou } \\
\text { desfrutam }\end{array}$ & $\begin{array}{l}\text { Fornecimento de gametas } \\
\text { marinhos para toda a região }\end{array}$ \\
\hline 6 & & & & $\begin{array}{l}\text { Dispersão de } \\
\text { Sementes }\end{array}$ & $\begin{array}{l}\text { Espalhamento de } \\
\text { sementes e plantas } \\
\text { selvagens }\end{array}$ & $\begin{array}{l}\text { A dispersão de se- } \\
\text { mentes e esporos }\end{array}$ & $\begin{array}{l}\text { de plantas e outros } \\
\text { organismos que são } \\
\text { importantes para as } \\
\text { pessoas em uso e } \\
\text { não-uso }\end{array}$ & $\begin{array}{l}\text { Dispersão de sementes e } \\
\text { esporos da Mata Atlântica e de } \\
\text { ambientes costeiros associados } \\
\text { (restinga) }\end{array}$ \\
\hline
\end{tabular}


Fornecendo habitats para plantas e animais selvagens veiros (incluindo proteção do pool genético)

Controle de Pestes (inclusive bioinvasões) que podem ser úteis para nós
A presença de condições ecológicas

(geralmente habita-

ts) necessárias para sustentar populações de espécies que as pessoas usam ou desfrutam
Regulação biológica de várias espécies, inclusive de espécies comerciais (Garoupas, Badejos, etc.)
Composição

e condições

atmosféricas

Controle de

Doenças

Doenças que impedem ou

\begin{tabular}{|c|c|c|c|c|c|}
\hline & & & atmosféricas & ra e oceanos & \\
\hline 11 & $\frac{\bar{\pi}}{\frac{\pi}{\Xi}}$ & $\begin{array}{l}\text { Interações } \\
\text { diretas, in } \\
\text { situ e ao ar } \\
\text { livre, com } \\
\text { sistemas } \\
\text { vivos que } \\
\text { dependem } \\
\text { da presença } \\
\text { no ambiente } \\
\text { ambiental }\end{array}$ & $\begin{array}{l}\text { Interações } \\
\text { físicas e } \\
\text { experien- } \\
\text { ciais com } \\
\text { o ambiente } \\
\text { natural }\end{array}$ & $\begin{array}{l}\text { Características } \\
\text { dos sistemas vi- } \\
\text { vos que possibi- } \\
\text { litam atividades } \\
\text { que promovam } \\
\text { saúde, recupera- } \\
\text { ção ou diversão } \\
\text { por meio de } \\
\text { interações ativas } \\
\text { ou imersivas }\end{array}$ & $\begin{array}{l}\text { Usando o ambiente } \\
\text { para esporte e re- } \\
\text { creação; usando a } \\
\text { natureza para ajudar } \\
\text { a manter a forma }\end{array}$ \\
\hline
\end{tabular}
jam esforço físico e reduzem a produção de alimentos, materiais ou energia dos ecossistemas, ou sua importância cultural, pelo consumo de biomassa ou pela competição
A redução por in-

Controlando pestes e terações biológicas espécies invasoras

espécies

\section{competição}

Que de outra forma

poderiam impedir

ou reduzir a produ- Premissa de que o ambiente ção de alimentos, materiais ou energia probabilidade de ocorrência de
A redução por interações biológicas espécies da incidência de

dos ecossistemas,

ou sua importância cultural, impedindo ou prejudicando o funcionamento ecológico de espécies úteis

Regulação da

composição quí- Regulando nosso

mica da atmosfe- clima global

Regulação das concentrações de gases na atmosfera
As características ou qualidades biofísicas de espécies ou ecossistemas culturais). (ambientes / espaços envolvidos, utilizados ou usufruídos de maneiras que exicognitivo saudável garante a redução da

Garantia da redução de contá gio de organismos exógenos, tais como o Coral Sol (em comparação com estruturas artificializadas, onde verifica-se grande incidência destes organismos) doenças ou marés vermelhas que podem afetar os humanos ou os animais pescados ou produzidos nas mariculturas da região

Sequestro de carbono pela vegetação costeira, algas e animais protegidos pela $\mathrm{ReBio}$ $\begin{array}{ll}\text { clima ou oceanos } & \text { animais p } \\ \text { globais } & \text { Arvoredo }\end{array}$ resta e das ilhas que as tornam atrativas para caminhadas e as oportunidades para mergulho e natação
Qualidades ecológicas da flo- 
Características dos sistemas vivos que possibilitam atividades que promovam saúde, recuperação ou diversão por meio de interações passivas ou observacionais

Características dos sistemas vivos que permitem a investigação científica ou a criação do conhecimento ecológico tradicional
Características dos sistemas

14

Interações

intelectuais

e represen-

tativas com

o ambiente

natural

e treinamento

Características
Observando plantas e animais onde eles

vivem; usando a

natureza para deses-

tressar
As características ou qualidades biofísicas de espécies ou ecossistemas

(ambientes / espaços culturais)
... que são vistos / observados pelas pessoas ou desfrutados de outras formas passivas em virtude de sons e cheiros etc.
Observação de pássaros, baleias, répteis e o próprio mergulho contemplativo para apreciar a vida selvagem vivos que possi-

bilitam educação

dos sistemas

vivos que são

ressonantes em

termos de cultura

ou patrimônio

Características

dos sistemas

vivos que permi- A beleza da natureza

tem experiências

estéticas

\section{As características}

ou qualidades bio-

físicas de espécies

ou ecossistemas

(ambientes / espaços

culturais) ...
.. que são objeto de pesquisa in situ

Local de interesse científico especial tureza

Estudando a natu-

reza

\section{As coisas da natu-}

reza que ajudam as

pessoas a se identifi-

carem com a história

ou cultura de onde

vivem ou vêm

\section{As características}

ou qualidades bio-

físicas de espécies

ou ecossistemas

(ambientes / espaços culturais) ...

As características

ou qualidades bio-

físicas de espécies

ou ecossistemas

(ambientes / espaços

culturais) ...
... que são objeto

de ensino ou de-

senvolvimento de

habilidades

... que contribuem

para o patrimônio

cultural ou o conhe-

cimento histórico

As características

ou qualidades bio-

físicas de espécies

ou ecossistemas

(ambientes / espaços

culturais) ...
... apreciados por

sua beleza inerente
Local usado para atividades de educação ambiental e volunta-

riado para conservação

\section{Identificação local. O arqui-} pélago é uma referência na região.

(1)

Área de grande beleza natural 
Elementos de sistemas vivos que têm significado simbólico

Usando a natureza como emblema nacional ou local
... Que são reconheAs características ou cidos pelas pessoas qualidades biofísicas de espécies ou ecossistemas (cenários / paisagens /

por seu caráter cultural, histórico usados como emblemas ou significantes espaços culturais) ...

Interações espirituais, simbólicas e outras com o ambiente natural

indiretas,

remotas e geralmente internas com sistemas vivos que não exigem presença no ambiente ambiental

\begin{tabular}{ll}
\hline Elementos de & As coisas da natu- \\
sistemas vivos & reza que têm impor- \\
que têm signifi- & tância espiritual para \\
cado sagrado ou & as pessoas \\
religioso &
\end{tabular}

religioso

Elementos de sistemas vivos usados para entretenimento ou representação

As coisas da naturefilmes ou escrever livros
As características ou qualidades biofísicas de espécies ou ecossistemas (cenários / paisagens / espaços culturais) ...

As características ou qualidades biofísi-

za costumavam fazer cas de espécies ou

Características ou características As coisas da natu de sistemas vivos reza que pensamos com um valor de que deveriam ser existência

conservadas

\section{Características}

ou características As coisas da naturede sistemas vivos za que queremos que que possuem um as futuras gerações valor de opção desfrutem ou usem ecossistemas (ceespaços culturais) ...
As características ou qualidades biofísicas de espécies ou ecossistemas (cenários / paisagens / espaços culturais) ... nários / paisagens / ou icônico e que são de algum tipo
... que são considerados como tendo significado sagrado ou religioso para as pessoas.

.. que fornecem mapode ser comunicado a outras pessoas através de diferentes mídias para diversão ou diversão terial ou assunto que

A Rebio Arvoredo possui uma série de espécies emblemáticas, principalmente espécies endêmicas e ameaçadas, tais como as tartarugas marinhas que possuem um grande peso simbólico

O Calhau de São Pedro é um referência religiosa na região, pois é o Padroeiro dos Pescadores.

\section{A Fotografia Submarina, os} livros e os documentários sobre a ReBio Arvoredo

\section{... que as pessoas} procuram preservar por causa de suas qualidades não

Área designada como região selvagem com pouca influência do homem utilitárias
As características ou qualidades biofísicas de espécies ou ecossistemas (cenários / paisagens /

espaços culturais) ...
.. que as pessoas procuram preservar Conservação do Arquipélago e para as gerações futuras por qualquer futuras motivo suas espécies para as gerações

suas especi ou legado 
Ambiental Costa dos Corais, UC de uso sustentável, localizada em Pernambuco e Alagoas, foram analisadas por meio de rede social, 1.984 fotografias tiradas por 207 usuários entre 2010 e 2016, destacando como serviço cultural a valorização da paisagem e a recreação social, refletindo claramente as atrações de uma praia tropical (Retka et al., 2019). Outros autores também afirmam que os SES culturais parecem se destacar em áreas protegidas (Nahuelhual et al., 2013; Palomo et al., 2013) ou em promontórios costeiros (Oliveira et al., 2018).

\subsection{Impactos da ReBio sobre os serviços ecossistêmicos e os stakeholders}

Foi possível verificar que existem cinco (5) impactos negativos (dois de provisão e três culturais) e dezesseis (16) impactos positivos (oito de regulação e oito culturais) (Tabela 3 e Figura 3) decorrentes da implementação e manutenção da ReBio do Arvoredo. Todos os impactos se distribuem de maneira diferenciada sobre os atores sociais e com intensidades variadas.

Os impactos negativos encontrados foram relacionados ao extrativismo, principalmente em relação à pesca, pois afeta todas as suas modalidades (artesanal, industrial e a caça submarina) e uma grande quantidade de pessoas pertencentes a estes grupos. A pesca artesanal ocorria por toda a região, e o arquipélago do Arvoredo era uma referência importante como local de pesca, e a proibição afetou a distribuição espacial das frotas pesqueiras, contudo, a atividade continua até hoje e é realizada ao redor da ReBio com relativa expressividade na produção local, portanto, a sensibilidade e a magnitude foram consideradas médias, uma vez que apenas o esforço (deslocamento) da frota foi afetado. O extrativismo de espécies vegetais (plantas, fungos e algas) foi considerado insignificante.

Os pescadores artesanais também foram afetados em relação à identificação local, pois existia uma tradição dos pescadores locais em utilizar às ilhas do Arvoredo como local de encontro e confraternização com seus pares e a implantação da ReBio não permitiu mais esse costume. O trabalho de Salvador $e t$ al. (2017) corrobora esse resultado, pois exemplifica o papel emblemático das ilhas da reserva na cultura e histórias de vida dos habitantes da região, sendo este impacto também considerado como de ordem moderada.

As atividades de recreação em contato com a natureza e o ecoturismo também foram afetadas negativamente, impactando principalmente o turismo, representados pelas empresas de mergulho da região. Estas atividades não podem ser mais realizadas devido ao regime de uso da categoria Reservas Biológica (IBAMA, 2004). O Plano de Manejo da ReBio prevê atividades educativas (IBAMA, 2004), algumas sendo realizadas, mas o mergulho oferecido pelas agências de turismo não se configura como tal. Na análise, esta proibição foi considerada como um impacto insignificante, uma vez que a sensibilidade dos turistas é baixa e a magnitude insignificante, devido a existência de inúmeras outras opções e de muitos turistas nem se quer conhecerem o arquipélago. No caso dos serviços ecossistêmicos de recreação, associado principalmente ao mergulho autônomo, as empresas desta atividade foram as mais afetadas, uma vez que esta ficou limitada apenas à porção sul da maior ilha do arquipélago, $o$ Arvoredo. Isto acarretou em custos maiores de deslocamento, principalmente para as operadoras da região de Bombinhas, e uma limitação das opções nos pacotes turísticos de mergulho na região, afetando a demanda e a arrecadação destas empresas. 
TABELA 3 - Impactos da Reserva Biológica Marinha do Arvoredo sobre os serviços ecossistêmicos.

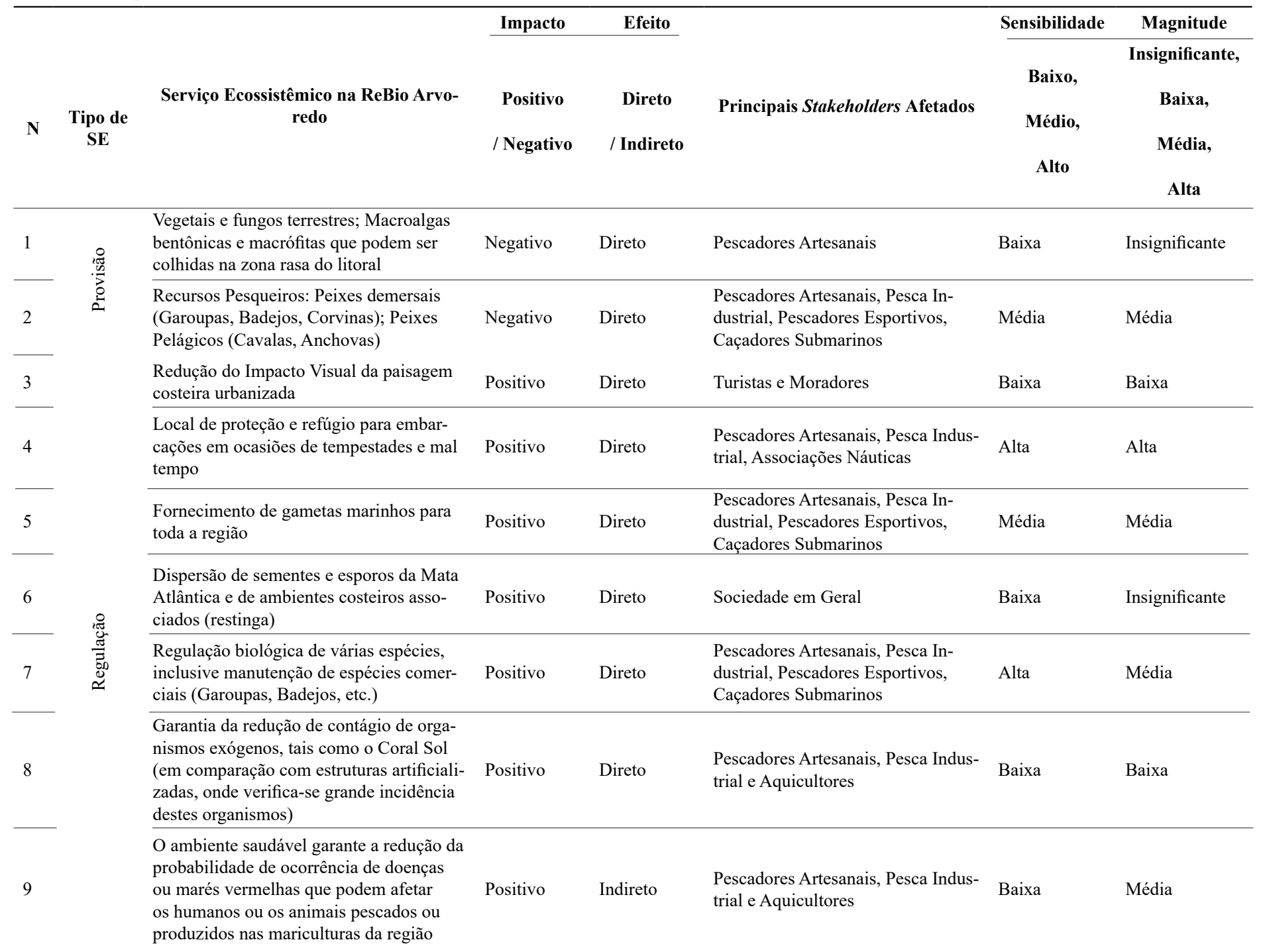


Sequestro de carbono pela vegetação, algas e animais protegidos pela ReBio Arvoredo

Positivo Indireto Sociedade em Geral Baixa $\quad$ Baixa

Qualidades ecológicas da floresta e das

ilhas que as tornam atrativas para cami-

nhadas e as oportunidades para mergulho

Negativo Direto

Empresas de Mergulho, Mergulhado-

e natação

Observação de pássaros, baleias, répteis

e o próprio mergulho contemplativo para apreciar a vida selvagem

(n)

$-$

Local que promove o conhecimento ecológico tradicional e de interesse científico especial

Negativo Direto

Empresas de Mergulho, Mergulhadores, Turistas, Órgãos de Turismo

Alta

Média

Local usado para atividades de educação ambiental e voluntariado para conservação

\begin{tabular}{|c|c|c|c|c|c|}
\hline $\begin{array}{l}\text { Identidade local. O arquipélago é uma } \\
\text { referência representativa na região. }\end{array}$ & Negativo & Direto & Pescadores Artesanais & Média & Média \\
\hline Área de grande beleza natural & Positivo & Direto & Turistas, Secretarias de Turismo & Média & Baixa \\
\hline $\begin{array}{l}\text { A ReBio Arvoredo possui uma série de } \\
\text { espécies emblemáticas, principalmente } \\
\text { endêmicas e ameaçadas (corais e tarta- } \\
\text { rugas marinhas) que possuem um peso } \\
\text { simbólico }\end{array}$ & Positivo & Direto & Órgãos Ambientais, Universidades & Alta & Alta \\
\hline $\begin{array}{l}\text { O Calhau de São Pedro é uma referência } \\
\text { religiosa na região. A procissão de São } \\
\text { Pedro ocorre todo ano nas comunidades } \\
\text { pesqueiras próximas. }\end{array}$ & Positivo & Indireto & Pescadores Artesanais & Baixa & Baixa \\
\hline $\begin{array}{l}\text { A Fotografia Submarina, os livros e os } \\
\text { documentários sobre a ReBio Arvoredo }\end{array}$ & Positivo & Direto & $\begin{array}{l}\text { Empresas de Mergulho, Mergulhado- } \\
\text { res, Universidades, Órgãos Ambien- } \\
\text { tais, Secretarias de Turismo }\end{array}$ & Média & Baixa \\
\hline $\begin{array}{l}\text { Área designada como região selvagem } \\
\text { com pouca influência do homem }\end{array}$ & Positivo & Direto & Universidades, Órgãos Ambientais & Alta & Alta \\
\hline $\begin{array}{l}\text { Conservação do Arquipélago e suas espé- } \\
\text { cies para as gerações futuras }\end{array}$ & Positivo & Direto & Sociedade em Geral & Média & Alta \\
\hline
\end{tabular}


O segmento da atividade turística tem crescido substancialmente, sendo que o mergulho tem motivado o turismo em locais pouco visitados por outros tipos de turistas, incluindo ilhas isoladas e partes inabitadas das costas continentais (Rowe \& Santos, 2016). O impacto disto foi considerado de média magnitude, pois limitou o mercado associado na região, sendo que uma sensibilidade alta dos atores foi atribuída a esta perda. Este impacto não foi considerado ainda maior, pois existem opções e alternativas de mergulho na região como demonstrado por Silva (2007). Conflitos entre uso recreacional para mergulho e outros interesses de pesca comercial e de conservação foram observados nas Áreas Marinhas Protegidas da Escócia (Jobstvogt et al., 2014).

Alguns serviços ecossistêmicos ganham maior peso por se tratar de uma reserva biológica, pois os serviços ecossistêmicos culturais de valor de existência ${ }^{4}$ e valor de opção/legado ganham maior peso na análise devido ao reforço e promoção das políticas de conservação da biodiversidade. Os impactos positivos afetam uma gama maior e variada de atores sociais, inclusive, e podem ser melhor aproveitados se novas estratégias de comunicação, educação e voluntariado promover e capitalizar estes benefícios.

Os impactos positivos do valor de existência, a proteção das embarcações, as espécies emblemáticas, a regulação biológica e a pesquisa científica são os mais expressivos da ReBio Arvoredo (Figura 3). Os impactos do valor de existência e das espécies emblemáticas foram considerados de alta sensibilidade e alta magnitude, pois são os principais aspectos da criação de uma ReBio, impactando a sociedade em geral, mas principalmente os órgãos ambientais e as ONGs Ambientalistas. Segundo o SNUC é objetivo da categoria
Reserva Biológica a "preservação integral da biota e demais atributos naturais existentes em seus limites" (Brasil, 2000). Outro impacto similar foi a regulação biológica, no entanto a magnitude desta foi considerada média, pois impacta majoritariamente os atores locais.

$\mathrm{O}$ uso das ilhas como um refúgio náutico para tempestades e mal tempo também foi um dos principais impactos positivos, uma vez que previne danos, acidentes e perda de vidas. No Plano de Manejo da ReBio Arvoredo é prevista dentro da Zona Conflitante a possibilidade de arribada (IBAMA, 2004). Os impactos decorrentes da criação e produção de conhecimento científico e conhecimento ecológico local também foram considerados altos, com maior expressão para a investigação científica e impactos para as universidades, institutos de pesquisa e seus pesquisadores, conforme Misturini \& Fonseca (2015). Cabe citar que a legislação preconiza o investimento e compensações ambientais em pesquisa nas unidades de conservação brasileiras, portanto esse é um impacto exclusivo da criação e manutenção da ReBio Arvoredo na região.

No caso da regulação biológica, associada com à exportação de gametas o efeito foi alto e positivo, pois ocorre um dos benefícios mais tangíveis, principalmente para os caçadores submarinos, os pescadores artesanais e os pescadores esportivos, uma vez que a ReBio Arvoredo garante a manutenção das populações de peixes explorados, exportando indivíduos para suas áreas lindeiras e garantindo animais maiores, com biomassa corporal até quatro vezes maior que os mesmos animais fora da reserva, principalmente nos peixes de costão rochoso, tais como a Garoupa (Epinephelus marginatus) e o Badejo-mira (Mycteroperca acutirostris). (Anderson et al., 2018). Este resultado reforça a eficácia da ReBio Arvoredo e a importância da manutenção e fiscalização

\footnotetext{
${ }^{4}$ Entende-se por valor de existência a parte do valor de um bem ou serviço ambiental que independe do seu uso presente ou futuro (Nogueira \& Medeiros, 1999).
} 
destas áreas de proteção biológica como um elemento fundamental da gestão pesqueira.

Os impactos positivos de intensidade moderada foram a educação e o voluntariado, o fornecimento de gametas e a responsabilidade com as futuras gerações. A ReBio Arvoredo executa uma série de atividades de educação ambiental e voluntariado, atendendo principalmente instituições de ensino com grupos agendados. São atividades executadas pelo ICMBio, mas há no "Programa de Voluntariado em Unidades de Conservação" parceria com a Fundação de Meio Ambiente de Bombinhas - FAMAB para atuação no Parque Natural Municipal Morro do Macaco. Também são realizadas na ReBio aulas de mergulho pela UNIVALI. Quanto a responsabilidade com as futuras gerações também foi considerada um impacto moderado, pois apesar da alta magnitude existe uma baixa sensibilidade ao tema.

Os impactos positivos de menor intensidade foram o controle de doenças e a inspiração e produção artística. No caso do controle de doenças foi considerado de baixa magnitude, pois as marés vermelhas ainda são um evento raro, com média sensibilidade aos aquicultores e pescadores da região, apesar da maré vermelha ter sido observada na Lagoa da Conceição, em Florianópolis, assim como em levantamentos aéreos que mostraram que as Marés Vermelhas podem se estender em trechos de até $10 \mathrm{~km}$ ao longo do litoral centro-norte catarinense (Proença, 2004). A inspiração artística está ligada principalmente a produção de livros, documentários e a fotografia submarina, sendo destacada as fotografias publicadas em Segal et al. (2017), bem como alguns produtos divulgados nas mídias sociais e propagandas das empresas de mergulho da região.

Os demais impactos, apesar de importantes, foram desconsiderados seja pela baixa sensibilidade ou pela baixa magnitude dos efeitos sobre os atores sociais. Isto deve-se principalmente à baixa tangibilidade destes impactos ou, ainda, a alta abstração destes para que as pessoas em geral consigam reconhecê-los e valorizá-los melhor. Alguns destes, tais como a redução do impacto visual, a regulação climática, a beleza natural e o controle de pestes (bioinvasões) possuem um tácito potencial se a gestão da ReBio Arvoredo ou pesquisadores consigam articular e comunicar seus efeitos sobre a sociedade.

No caso da beleza natural este carece de melhor articulação com os órgãos e atividades de turismo, uma vez que a boa transparência das águas e a configuração das ilhas conferem uma complexidade estrutural da paisagem marinha que pode ser melhor aproveitada como um emblema e atrair turistas para a região de entorno da ReBio. A beleza cênica como potencial ao mergulho deve ser destacada como atividade educativa e não recreativa, considerando as restrições da categoria de UC. Além disto, Rowe \& Santos (2016) destacam que a atividade turística tem crescido substancialmente, oferecendo oportunidades, mas também ameaças relevantes para os destinos turísticos. Por outro lado, os atributos naturais da Reserva resultam em potencial para contemplação da paisagem, mesmo que a distância. Os elementos água, naturalidade e complexidade topográfica são destacados nas preferências paisagísticas (Marenzi \& Roderjan, 2005; Felix et al., 2016; Belino et al., 2018). Os órgãos de turismo podem ser atores beneficiados e com maior capacidade de articular esse potencial paisagístico e cultural juntamente aos públicos, tanto para os empreendimentos ligados ao turismo como aos próprios turistas. A figura 3 sintetiza graficamente todos os impactos identificados sobre os serviços ecossistêmicos na ReBio Arvoredo. 


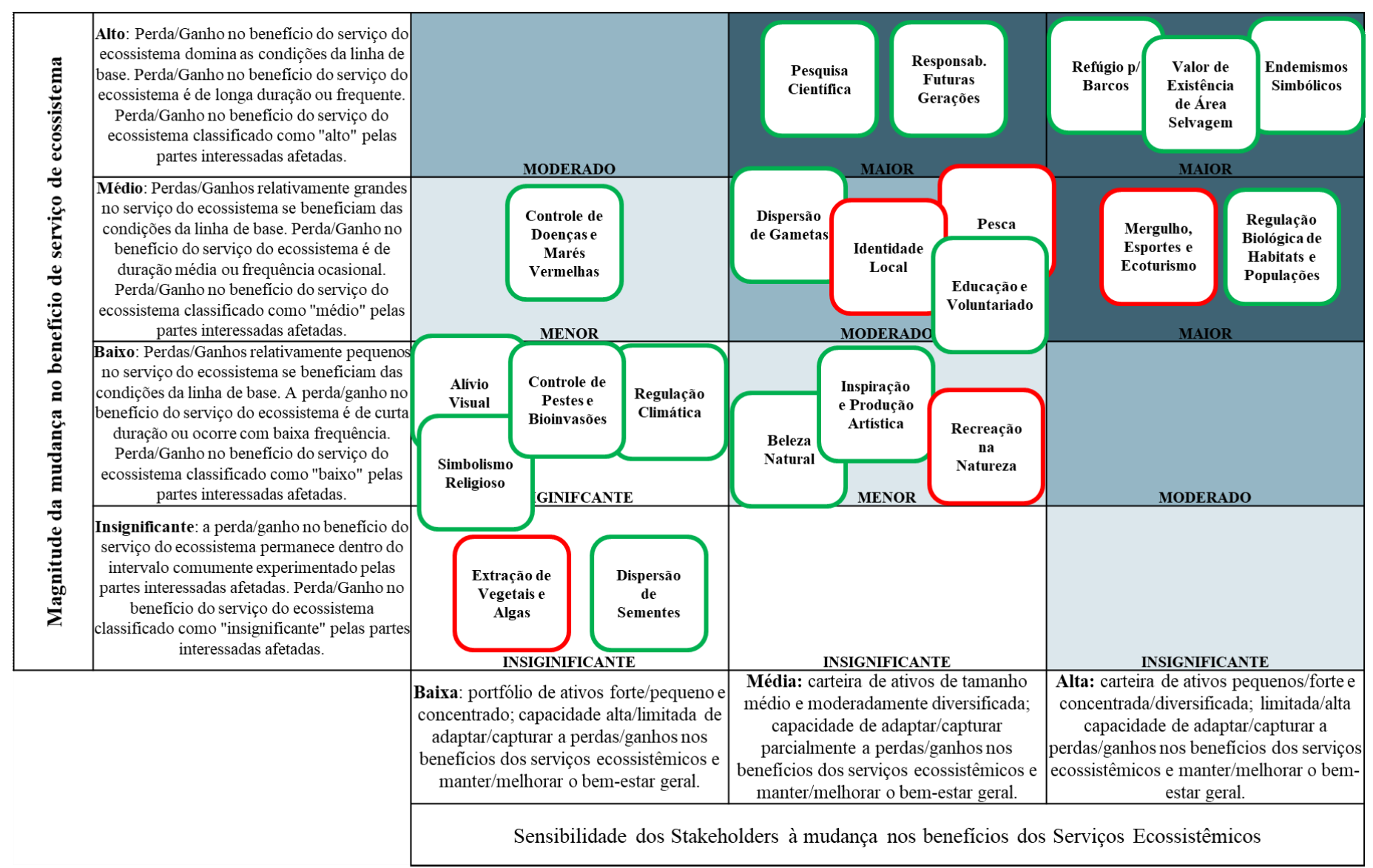

FIGURA 3 - Matriz dos impactos da Reserva Biológica sobre os serviços ecossistêmicos. 


\section{Conclusões}

A abordagem metodológica apresentada conseguiu destacar os principais pontos a serem trabalhados na gestão e no relacionamento da ReBio com seu entorno, seja para diminuir os riscos relativos aos impactos negativos e a reatividade de alguns stakeholders, ou ampliar oportunidades relacionadas aos efeitos positivos da UC. Bennet (2016) corrobora o resultado e atesta que uma melhor incorporação de evidências das ciências sociais e naturais, através da integração de uma pluralidade de métodos ao monitoramento e avaliação fornecem uma imagem mais completa sobre a qual basear as decisões de conservação e o gerenciamento ambiental.

Os resultados reforçam a importância da adoção de uma visão pluralista de métodos e evidências na ciência da conservação, que incluem dados sociais qualitativos produzidos rigorosamente, bem como conhecimento local e tradicional, todos os quais podem ser usados para orientar ou melhorar políticas de conservação, ações de gerenciamento e resultados ecológicos. Em vez de desprezar algumas formas de evidência, uma abordagem pragmática da ciência da conservação exige considerar todas as disciplinas e métodos ao procurar entender riscos sociais, problemas da conservação e todas as informações disponíveis na busca de soluções eficazes.

Os problemas identificados em relação ao distanciamento de alguns dos stakeholders, pela falta de participação ou estratégias efetivas de engajamento, pode levar a perda de oportunidades ou a promoção e adesão do público à bandeira da conservação. Os métodos atuais, muitas vezes, fornecem insights limitados sobre erros de governança ou de quais deficiências de gerenciamento estão ocorrendo nesse contexto. Isto pode gerar desconfianças e resistências, ou uma sensação de ineficácia das políticas de conservação, acarretando em maior fragilidade do sistema como um todo.

Não obstante, a reação dos stakeholders em relação aos impactos negativos da ReBio Arvoredo não pode ser negligenciada, pois apesar da capacidade de adaptação dos atores dependentes dos SES verifica-se campanhas e esforços para a recategorização da ReBio Arvoredo. Este passivo implica na elaboração de melhores estratégias de mitigação, adaptação e relacionamento com estas partes, atenuando os conflitos vigentes, muitos dos atores prejudicados estão distanciados da relação com o Conselho da ReBio, uma vez que estes não foram compensados pelos impactos e também não conseguiram se adequar de maneira satisfatória às restrições impostas pela ReBio. A discussão sobre a categorização ilustra um risco social grave, não só para o Arvoredo, mas para toda a gestão das unidades de conservação brasileiras, podendo gerar precedentes jurídicos com grande potencial de danos à biodiversidade brasileira.

Há necessidade de maior articulação e comunicação com a sociedade em escala regional que enalteça os impactos positivos gerados pela ReBio, de uma maneira mais clara e tangível aos usuários identificados. O distanciamento e a ausência dos órgãos de turismo no Corbio, ilustra essa lacuna, pois poderia haver campanhas de divulgação ou ações de comunicação mais diretas à sociedade e aos turistas que vem à região. Os impactos positivos podem ser utilizados de maneira estratégica, consolidando ações de promoção e integração da conservação da biodiversidade marinha na socioe- 
conomia da região, tal como a geração de empregos e novos negócios associados à proteção da natureza.

O presente trabalho demonstrou que é possível aplicar o conceito dos serviços ecossistêmicos de maneira pragmática, integrando-o na gestão e planejamento, desde que se preste atenção aos interesses, aos impactos gerados, às relações sociais e a realidade da gestão das unidades de conservação brasileiras. A metodologia desenvolvida pode ser replicada em outras unidades de conservação e este conhecimento produzido pode ser utilizado para ampliar o entendimento sobre o papel dos ecossistemas no bem-estar humano e, estrategicamente, ajudar os órgãos ambientais, a articular e comunicar seus interesses e preocupações em relação aos impactos negativos e aos benefícios gerados pelas unidades de conservação brasileiras.

\section{Referências}

Adams. M.; Sandbrook C. Conservation, evidence and policy. Oryx, 47, 329-335, 2013. doi: 10.1017/ S0030605312001470

Alencar, G. S. de. Biopolítica, Biodiplomacia e a Convenção sobre Diversidade Biológica/1992: Evolução e Desafios para Implementação. Revista de Direito Ambiental, 3(82), 1996.

Alexander, A.; Walker, H.; Naim, M. Decision theory in sustainable supply chain management: a literature review. Supply Chain Management: An International Journal, 19(5/6), 504-522, 2014.

Amaro, J. J. V. Sociedades Complexas e Risco Ecológico. Epistemologia e Meio Ambiente na Atual Teoria de Sistemas. NUPEAT-IESA-UFG, 3(1), 47-59, 2013. doi: 10.5216/teri.v3i1.27324

Anderies, J. M.; Janssen, M. A.; Ostrom, E. A framework to analyze the robustness of social-ecological systems from an institutional perspective. Ecology and Society, 9(1), 18,
2004. Disponível em: http://stakeholders.ecologyandsociety.org/vo19/iss1/art18

Anderson, A. B.; Batista, M. B.; Gibran, F. Z.; Félix-Hackradt, F. C.; Hackradt, C. W.; García-Charton, J. A.; Floeter, S. R. Habitat use of five key species of reef fish in rocky reef systems of southern Brazil: evidences of MPA effectiveness. Marine Biodiversity, 1(1), 2018. doi: 10.1007/ s12526-018-0893-6

Barnaud, C.; Corbera, E.; Muradian, R.; Salliou, N.; Sirami, C.; Vialatte, A.; Reyes-García, V. Ecosystem services, social interdependencies, and collective action: a conceptual framework. Ecology and Society, 23(1), 1-14, 2018. Disponível em: https://stakeholders.ecologyandsociety.org/ vol23/iss $1 / \operatorname{art15/}$

Belino, J. A. T.; Beltrão, M. C.; Marenzi, R. C. Análise da Qualidade Visual da Paisagem de Praias Arenosas na Orla de Itajaí-SC. Brazilian Journal of Aquatic Science and Technology, 21(2), 19-25, 2018. Disponível em: https:// siaiap32.univali.br/seer/index.php/bjast/article/view/12459

Bennett, N. J. Using perceptions as evidence to improve conservation and environmental management. Conservation Biology, 3(3), 1-11, 2016. doi: 10.1111/cobi.12681

Bennett, N. J., Dearden, P. From measuring outcomes to providing inputs: governance, management, and local development for more effective marine protected areas. Marine Policy, 50(A), 96-110, 2014. doi: 10.1016/j.marpol.2014.05.005

Bennett, N.J.; Roth, R. The conservation social sciences: what?, how? and why? Canadian Wildlife Federation and Institute for Resources, Environment and Sustainability, University of British Columbia, Vancouver, 2015. doi: 10.13140/2.1.2664.3529

Bodin, O.; Crona, B.I. The role of social networks in natural resource governance: What relational patterns make a difference? Global Environmental Change, 19(3), 366-374, 2009. doi: 10.1016/j.gloenvcha.2009.05.002

Boisot, M. Knowledge asset: securing a competitive advantage in the information economy. New York: Oxford University Press, 1998.

Bowd, R., N. W. Quinn; D. C. Kotze. Toward an analytical 
framework for understanding complex social-ecological systems when conducting environmental impact assessments in South Africa. Ecology and Society, 20(1), 41, 2015. Disponível em: https://stakeholders.ecologyandsociety.org/ vol20/iss1/art41/

Brasil. Lei no 9.985, de 18 de julho de 2000. Institui a Lei do Sistema Nacional de Unidades de Conservação da Natureza. Brasília: DOU de 18/07/2000.

Chevalier, J. M.; Buckles, D. J. A handbook for participatory action research, monitoring and evaluation. Ottawa, Ontario: SAS2, 2013.

Chludinski, A. P. Integração de dados oceanográficos e de sensoriamento remoto na análise espacial de águas costeiras visando a setorização da Reserva Biológica Marinha do Arvoredo e Baía de Tijucas, SC. Florianópolis, Dissertação (Mestrado em Geografia) - UFSC, 2002.

Chuenpagdee, R., Pascual-Fernandez, J. J., Szelianszky, E., Luis Alegret, J., Fraga, J., Jentoft, S. Marine protected areas: Re-thinking their inception. Marine Policy, 39(1), 234-240, 2013. doi: 10.1016/j.marpol.2012.10.016

Costa, R. G. Gestão compartilhada: uma Perspectiva para a Efetiva Implementação da Reserva Biológica Marinha do Arvoredo/SC. Florianópolis, Dissertação (Mestrado em Engenharia de Produção) - UFSC, 2003.

Dare, M.; Schirmer, J.; Vanclay, F. Community engagement and social license to operate. Impact Assessment and Project Appraisal, 32(3), 188-197, 2014.doi: 10.1080/14615517.2014.927108

de Snoo, G.R.; Herzon, I.; Staats, W.; Burton, R.J.F.; Schindler, S.; van Djik, J.; Lockhorst, A.M.; Bullock, J.M.; Lobley, M., Wrbka, T.; Schwarz, G. \& Musters, C.J.M. Toward effective nature conservation on farmland: making farmers matter. Conservation Letters, 6, 66-72, 2013. doi: 10.1111/j.1755-263X.2012.00296.x

Dick, J. et al. Stakeholders' perspectives on the operationalization of the ecosystem service concept: Results from 27 case studies. Ecosystem Services, 29(C), 2017. doi: 10.1016/j.ecoser.2017.09.015.

Evans, K.; Guariguata, M.R. Participatory monitoring in tropical forest management: a review of tools, concepts and lessons learned. Bogor, Indonesia: Center for International Forestry Research, 2008.

Felix, G.; Marenzi, R. C.; Polette, M.; Netto, S. A. Landscape visual quality and meiofauna biodiversity on sandy beaches. Environmental Management, 58(1), 682-693, 2016. doi: 10.1007/s00267-016-0735-x

Fischer, R. O Projeto de Lei n. 4.198/12 frente às metas de aichi para biodiversidade: uma análise da recategorização da Reserva Biológica Marinha do Arvoredo sob o enfoque do direito internacional ambiental. Florianópolis, TCC (Graduação em Direito) - UFSC, 2015.

Fortmann, L. Participatory research in conservation and rural livelihoods: doing science together.UK: Wiley-Blackwell, Chichester, 2008.

Freeman, R.E. Strategic management: a stakeholder approach. Boston: Pitman, 1984.

Garnett, S. T.; Zander, K. K.; Robinson, C. J. Social license as an emergent property of political interactions: Response to Kendal and Ford 2017. Conservation Biology, 32(3), 1-3, 2018. doi: $10.1111 /$ cobi.13113

Gujit, I. Participatory monitoring and evaluation for natural resource management and research. Chatham, United Kingdom: Natural Resources Institute, 1999.

Hacking, T.; Guthrie, P. Framework for clarifying the meaning of triple bottom-line, integrated, and sustainability assessment. Environmental Impact Assessment Review, 28(23), 73-89, 2008. doi: 10.1016/j.eiar.2007.03.002

Haines-Young, R.; Potschin, M.B. Common International Classification of Ecosystem Services (CICES). V 5.1 and guidance on the application of the revised structure, 2018. Disponível em: < https://cices.eu/content/uploads/ sites/8/2018/01/Guidance-V51-01012018.pdf >. Acesso em: jan. 2020.

Henrichs, A. B.; Baulcomb, C.; Koss, R.; Hussain, S. S.; de Groot, R. S. Typology and indicators of ecosystem services for marine spatial planning and management. Journal of Environmental Management, 130(1), 135-145, 2013. doi: 10.1016/j.jenvman.2013.08.027

Hockings, M.; Stolton, S.; Leverington, F; Dudley, N.; Courrau, J. Evaluating effectiveness: a framework for assessing 
the management effectiveness of protected areas. Gland, Switzerland: International Union for the Conservation of Nature, 2nd ed., 2006.

IBAMA - Instituto Brasileiro do Meio Ambiente e Recursos Renováveis. Portaria IBAMA 81, de 10 de outubro de 2004. Aprova o plano de manejo da Reserva Biológica Marinha do Arvoredo. 2004. Brasília: DOU de 13/09/2004.

ICMBio - Instituto Chico Mendes de Conservação da Biodiversidade. Reserva Biológica Marinha do Arvoredo. Disponível em $<$ https://stakeholders.icmbio.gov.br/rebioarvoredo/ quem-somos/nossa-sede.html $>$. Acesso em: agosto de 2020.

Jobstvogt, N.; Watson, V.; Kenter, J.O. Looking below the surface: The cultural ecosystem service values of UK marine protected areas (MPAs). Ecosystem Services, 10(1), 97-110, 2014. doi: 10.1016/j.ecoser.2014.09.006

Kareiva, P.; Marvier, M. What is Conservation Science? BioScience, 62(1), 962-969, 2012. doi: 10.1525/bio.2012.62.11.5

Landsberg, F., J.; Treweek, M.M.; Stickler, N.; Henninger, \& O. Venn. Weaving Ecosystem Services. Into Impact Assessment Technical Appendix (Version 1.0). Washington, DC: World Resources Institute, 2014. Disponível em: <http:// stakeholders.wri.org/sites/default/files/weaving_ecosystem_services_into_impact_assessment_technical_appendix.pdf $>$. Acesso em: janeiro de 2018.

Liquete, C.; Piroddi, C.; Drakou, E. G.; Gurney, L.; Katsanevakis, S.; Charef, A.; Egoh, B. Current status and future prospects for the assessment of marine and coastal ecosystem services: a systematic review. PLoS ONE, 8 (e67737), 2013. doi: 10.1371/journal.pone.0067737

Mannetti, L. M.; Göttert, T.; Zeller, U. and Esler, K.J. Identifying and categorizing stakeholders for protected area expansion around a national park in Namibia. Ecology and Society, 24(2), 2019. doi: 10.5751/ES-10790-240205

Marenzi, R. C.; Roderjan, C. V. Estrutura espacial da paisagem da morraria da Praia Vermelha (SC): subsídio à ecologia de paisagem. Revista Floresta, 35(2), 259-269, 2005. doi: 10.5380/rf.v35i2.4614

Marques, C. D. L. O fortalecimento da interface entre ciência e política no brasil para a conservação da biodiversidade: avaliação dos instrumentos atuais e propostas de integração da lista vermelha de ecossistemas. Nazaré Paulista, Dissertação (Mestrado Profissional em Conservação da Biodiversidade e Desenvolvimento Sustentável) - ESCAS-IPÊ, 2017.

Medeiros, R. Desafios à gestão sustentável da biodiversidade no Brasil. Floresta e Ambiente, 13(2), 01-10, 2006.

Medeiros, R. P.; Guanais, H.; Santos, L. O.; Spach, H.; Silva, C. N. S.; Foppa, C. C.; Cattani, A. P..; Rainho, A. P. Strategies for bycatch reduction at small-scale shrimp trawl fishing: perspectives for fisheries management. Boletim do Instituto de Pesca, 39(3), 339-358, 2018. Disponível em: https://stakeholders.pesca.sp.gov.br/boletim/index.php/bip/ article/view/1001

Misturini, D. \& Fonseca, A. C. Reserva Biológica Marinha do Arvoredo: 25 anos de pesquisa em uma base de dados. Seminário de pesquisa e iniciação científica do Instituto Chico Mendes de Conservação da Biodiversidade. Anais do VII Seminário de pesquisa e iniciação científica do Instituto Chico Mendes de Conservação da Biodiversidade: conservação. Brasilia: ICMBio, 2015.

Mitchell, R. K.; Agle, B. R.; Wood, D. J. Toward a theory of stakeholder identification and salience: defining the principle of who and what really counts. The Academy of Management Review, 22(4), 853-886, 1997.

Nahuelhual, L.; Carmona, A.; Lozada, P.; Jaramillo, A.; Aguayo, M. Mapping recreation and ecotourism as a cultural ecosystem service: an application at the local level in Southern Chile. Applied Geography, 40(1), 71-82, 2013. doi: 10.1016/j.apgeog.2012.12.004

Nogueira, J.M.; Medeiros, A.A. Quanto vale aquilo que não tem valor? Valor de existência, economia e meio ambiente. Cadernos de Ciência \& Tecnologia, 16(1), 59-83, 1999.

Oliveira, C.; Marenzi, C. R.; Longarete, C. Serviços ecossistêmicos prestados pelos promontórios costeiros no litoral Centro-norte de Santa Catarina. Brazilian Journal of Aquatic Science and Technology, 21(2), 10-18, 2018. doi: 10.14210/bjast.v21n2.11172

Palomo, I.; Martín-López, B.; Potschin, M.; Haines-Young, R.; Montes, C. National Parks, buffer zones and surrounding lands: mapping ecosystem service flows. Ecosystem Services, 4(1), 2013. doi: 10.1016/j.ecoser.2012.09.001 
PETROBRAS. Relatório técnico semestral do projeto de monitoramento da atividade pesqueira na Bacia de Santos (PMAP-BS). Junho de 2017. Disponível em: <https://stakeholders.comunicabaciadesantos.com.br/sites/default/files/ Relatorio_Tecnico_Semestral_PMAP-BS_jan-jun_2017. pdf $>$. Acesso em: nov. de 2020.

Pomeroy, R.S.; Parks, J.E.; Watson, L.M. How is your MPA doing? A guidebook of natural and social indicators for evaluating marine protected area management effectiveness. Gland, Switzerland: International Union for the Conservation of Nature, 2004.

Potts, T.; Burdon, D.; Jackson, E.; Atkins, J.; Saunders, J.; Hastings, E.; Langmead, O. Do marine protected areas deliver flows of ecosystem services to support human welfare? Marine Policy, 44(1), 139-148, 2014. doi: 10.1016/j. marpol.2013.08.011

Pretto, D. J.; Marimon, M. P. C. Desafios à gestão participativa na perspectiva dos gestores e conselheiros da Reserva Biológica Marinha do Arvoredo, Santa Catarina. Desenvolvimento e Meio Ambiente, 42, 2017. doi: 10.5380/ dma.v42i0.

Proença, L. A. de O. A red water caused by Mesodinium rubrum on the coast of Santa Catarina, southern Brazil. Brazilian Journal of Oceanography, 52(2), 153-161, 2004. doi: 10.1590/S1679-87592004000200007

Pullin, A. S.; Sutherland, W.; Gardner, T.; Kapos, V.; Fa, J. Conservation priorities: identifying need, taking action and evaluating success. Key Topics in Conservation Biology, 2(1), 3-22, 2013. doi: 10.1002/9781118520178.ch1

Reed, M.S.; Graves, A.; Dandy, N.; Posthumus, H.; Hubacek, K., Morris, J.; Prell C.; Quinn, C.H. \& Stringer, L.C. Who is in and why? A typology of stakeholder analysis methods for natural resource management. Journal of Environmental Management, 90(1), 1933-1949, 2009.

Retka, J.; Jepson, P.; Ladle, R. J.; Malhado, A. C. M.; Vieira, F. A. S.; Normande, I. C.; Souza, C. N.; Bragagnolo, C.; Correia, R. A. Assessing cultural ecosystem services of a large marine protected area through social media photographs. Ocean \& Coastal Management, 176(1), 40-48, 2019. doi: 10.1016/j.ocecoaman.2019.04.018

Rowe, R. W. G.; Santos, G. E. O. Turismo de mergulho: análise do comportamento de viagem dos mergulhadores brasileiros. Caderno Virtual de Turismo, 16(3), 61-75, 2016. doi: 10.18472/cvt.16n3.2016.1061.

Sales, G. Gestão de unidades de conservação federais no brasil: burocracia e poder simbólico. Florianópolis, Dissertação (Mestrado em Administração) - UFSC, 2010.

Sales, G. Seguindo tartarugas e tubarões na análise de uma política pública para a conservação da natureza. Florianópolis, Tese (Doutorado em Administração) - UFSC, 2017.

Salvador, A.S. do N.; Reis, L.B; Bueno, L. A Ocupação da Ilha do Arvoredo e do Litoral Catarinense: uma história de longa duração. In: Segal, B.; Freire, A.S.; Lindner, A.; Krajewsky, J. P.; Soldateli, M. (Orgs.). MAArE Monitoramento ambiental da Reserva Biológica Marinha do Arvoredo e entorno. Florianópolis: UFSC/MAArE, 1. ed., 2017.

Schreckenberg, K.; Camargo, I.; Withnall, K.; Corrigan, C.; Franks, P.; Roe, D.; Scherl, L. M.; Richardson, V. Social assessment of conservation initiatives: a review of rapid methodologies. London: Natural Resource Issues, 22. IIED, 2010.

Segal, B.; Freire, A.S.; Lindner, A.; Krajewsky, J. P.; Soldateli, M. (Orgs.). MAArE Monitoramento Ambiental da Reserva Biológica Marinha do Arvoredo e entorno. Florianópolis: UFSC/MAArE, 1. ed., 2017.

Silva, T. F. F. Análise integrada da problemática do turismo submarino no município de bombinhas e entorno da Reserva Biológica Marinha do Arvoredo - SC. Itajaí, Trabalho de Conclusão de Curso (Graduação em Ciências Biológicas), UNIVALI, 2007.

Smith, A.; Stirling, A. The politics of social-ecological resilience and sustainable socio-technical transitions. Ecology and Society, 15(1): 11, 2010. Disponível em: http:// stakeholders.ecologyandsociety.org/vol15/iss 1/art11/

Snowden, D. The origins of Cynefin, part 1-7. Disponível em: http://cognitive-edge.com/blog/entry/3505/part-one-origins-of-cynefin. Acesso em: jan. 2017.

Snowden, D. Complex adaptative systems theory and distributed ethnography - a sense of direction. In: Palestra organizada por Cognitive Edge. São Paulo, abr. 2018.

Sowman, M.; Sunde, J. Social impacts of marine protected 
areas in South Africa on coastal fishing communities. Ocean \& Coastal Management, 157(1), 168-179, 2018. doi: 10.1016/j.ocecoaman.2018.02.013

Strenzel, G. M. R. Programa de monitoramento ambiental da reserva biológica marinha do Arvoredo: uma proposta metodológica. Florianópolis, Dissertação (Mestrado em Geografia) - UFSC, 1997.

UNEP - United Nations Environment Programme, United Nations Statistics Division, Convention on Biological Diversity. SEEA experimental ecosystem accounting: technical recommendations. Consultation draft -4.1(6), 2017. Disponível em: < https://unstats.un.org/unsd/envaccounting/ eea_project/tr_consultation/seea_eea_tech_rec_consultation_draft_ii_v4.1_march2017.pdf $>$. Acesso em: abr. 2019.

Vivacqua, M. Conflitos socioambientais no litoral de Santa Catarina: o caso da Reserva Ecológica Marinha do Arvoredo. Florianópolis, Dissertação (Mestrado em Geografia) - UFSC, 2005.
Voyer, M.; Gladstone, W.; Goodall, W. Obtaining a social licence for MPAs - influences on social acceptability. Marine Policy, 51(1), 260-266, 2015. doi: 10.1016/j.marpol.2014.09.004

Wahrlich, R. A Reserva Biológica Marinha do Arvoredo (SC) e a atividade pesqueira regional. Florianópolis, Dissertação (Mestrado em Geografia) - UFSC, 1999.

Wallace K. J. Classification of ecosystem services: Problems and solutions. Biological Conservation, 139(1), 235-246, 2007. doi: 10.1016/j.biocon.2007.07.015

Zurlini, G., Petrosillo, I.; Cataldi, M. Socioecological Systems. In: Jørgensen, S.E.; Fath, B.D. (Eds). Encyclopedia of Ecology. Oxford, UK: Elsevier, 2008. p. 3264-3269. 